\title{
The Creative Journey of Grounded Theory Analysis: A Guide to its Principles and Applications
}

\author{
Anna Dourdouma ${ }^{1 凶} \&$ Kathrin Mörtl ${ }^{1}$
}

\begin{abstract}
Grounded theory analysis is a method widely used by qualitative researchers. This method interprets empirical materials to formulate a theory about a particular social phenomenon. In this article, we describe the steps of grounded theory method, which comprises open coding of the material followed by the grouping of open codes into categories that are increasingly abstracted to capture the essential meaning of the phenomenon. This depiction is offered as a set of explicit guidelines for researchers interested in the method.
\end{abstract}

Keywords: grounded theory, methodology, guidelines, qualitative research

Grounded theory analysis is described as a flexible approach to studying language and meaning-making in the social world (McLeod, 2011). It is attractive to researchers who prefer to immerse themselves in the data before formulating a theory and who enjoy working with natural language (Rennie, 1998a, $1998 \mathrm{~b})$. Grounded theory method can be used not only with qualitative data, such as interview transcripts, discourse and observational notes, but also with arrays of quantitative data (Glaser \& Strauss, 1967). Any source of information that helps to explore and understand a specific phenomenon of interest can produce data for a grounded theory analysis.

Grounded theory analysis was first introduced in the 1960 s by two sociologists, Glaser and Strauss, as a method for using preexisting data to conceptualize theories. At the time, this method was an important innovation that contrasted with the conventional, deductive theorizing typically used in sociology. Grounded theory method has been applied to a wide range of topics by qualitative researchers and has been adopted by other health and social science disciplines, including counseling and psychotherapy.

The Discovery of Grounded Theory was published by Glaser and Strauss in 1967. This work emphasizes

\footnotetext{
${ }^{1}$ Sigmund Freud University Vienna, Department of Psychotherapy Science, Austria.

$\square$ Correspondence concerning this article should be addressed to A. Dourdouma, Sigmund Freud University Vienna, Department of Psychotherapy Science, Schirchgasse 9a, 1030 Vienna, Austria. Email: a.dourdouma@yahoo.com
}

the approach's three main principles: First, that the researcher should discover new meanings in the social world; second, that the aim is to generate a theory for better understanding the phenomenon being investigated; and third, that this theory should be grounded in the data (McLeod, 2011). Glaser and Strauss had diverse backgrounds, and this diversity was reflected in their individual versions of the method. Glaser $(1978$; 1992) was a student of Lazarsfeld and Zetterberg at Columbia University and had a comparatively more quantitative orientation. Strauss (1987; Strauss \& Corbin, 1990, 1998) hailed from the Chicago School of Sociology, which emphasized ethnography and pragmatism. While there, he conducted field studies of psychiatric institutions. Although these approaches were complementary in the beginning (Strauss in an interview from 1994; Legewie, 2004), the differences later led to a schism between Glaser and Strauss (see the exchange between Rennie, 1998a, 1998b, and Corbin, 1998). Some contemporary authors argue that Glaserian and Straussian grounded theory are two profoundly different procedures (Strübing, 2007). Although a comprehensive overview of the coding procedures will be given later on, it is important to address this issue, albeit briefly. To provide an overview of terminology specific to grounded theory, it is necessary to understand the method in its historical context and to describe its development over time.

Reviewing the literature on this topic, Mey and Mruck (2007) compare Glaser's (1978) basic coding procedures with those of Strauss (1987) and Strauss 
and Corbin (1990). ${ }^{1}$ To preface this comparison, it should be noted that in the original 1967 work, Glaser and Strauss used the term "coding" to refer to the activity that produces both codes and categories; the latter were more abstract than the former. Recently, the software Atlas.ti (see Gibbs, 2007; Muhr, 1994) has simplified its author's interpretation of Glaser's method by using the term "code" to refer to both codes and categories. In the case study presented below, we used the Atlas.ti software. Therefore, to make this overview consistent with our presentation of the case study, we shall use the term "coding." Although we use this wording throughout the text, we do not subscribe exclusively to Glaser's approach to grounded theory. This fact will become apparent when we implement a coding procedure (axial coding) that was introduced and labeled by Strauss and Corbin.

Glaser enumerates the steps of analysis as follows: First, open coding, or low-abstraction codes that use the constant comparison procedure, including what Glaser and Strauss (1967) referred to as in vivo codes, or codes that use pithy representations of experience provided by the participants themselves. Second, selective coding, which entails system modifications that focus on an emerging preliminary coding idea. The aim of this step is to reach code saturation, at which point new data will require no further coding. The third step is theoretical coding, or the emergence of a core idea expressed as a core code that is then used in theory development.

Alternatively, in Strauss and Corbin's work (1998; see also Strauss, 1987); Corbin \& Strauss, 2008), the procedural steps are open coding (as in Glaser's [1978, 1992] model); axial coding (analyzing a given code in terms of a coding paradigm and conditional matrix [see below] and relating the given code to other codes); and selective coding (integrating and refining code families to form a concept that results in the theoretical model).

The function and meaning of "selective coding" in Glaser's work places more emphasis on exploring the

\footnotetext{
${ }^{1}$ Mey and Mruck (2007) compare the two procedures in an elaborate literature review that begins on page 25 of their popular "Grounded Theory Reader," which consists of articles by leading grounded theory experts in the German and English language, including original interview material from Barney Glaser and Anselm Strauss.

${ }^{2}$ Specifically, some grounded theory researchers describe the results of open coding as "codes" (as can be seen in the grounded theory-based software Atlas.ti, which was highly influenced by Glaserian grounded theory) and identify higher level, or second-level codes, which include more interpretation and are therefore called "categories." Other grounded theory researchers argue that a low-abstraction "code" is already a low-abstraction category because it already involves interpretation. We use the following sequential labeling: codes, second-level codes, code families (which are groups of first- and/or second-level codes) and core categories. We agree that "codes" already involve interpretation. We chose this terminology based on our computer-assisted work with Atlas.ti, which uses the Glaserian terminology.
}

specific phenomenon/material under investigation and is not yet directed towards building the theory. It serves a perspective-giving function during the process of open coding, leading the researcher in a specific direction. In Strauss and Corbin's $(1990,1998)$ work, "selective coding" is the final step of the analysis. After the open codes are put into perspective and connected among each other (axial coding), the final selective coding step is focused on the emerging core code. According to the procedural sequence (from open coding to the core code and emerging grounded theory), the selective coding step in Strauss and Corbin's work can be compared to the theoretical coding step in Glaser's procedure, though it is not exactly the same. Additionally, Strauss and Corbin adopted and modified Glaser's notion of the "Basic Social Process" (which Glaser saw as a prominent member of his "coding families") when formulating what they called the "Coding Paradigm," which became a prominent part of their grounded theory procedure. Specifically, during axial coding, the researcher analyzes the given code in terms of (a) the coding paradigm, which comprises the conditions, context, actions and consequences of the behavior that is codified, and (b) what they term the "conditional matrix," or network of potentially relevant conditions that need to be taken into account when analyzing a given incident.

More recent versions of grounded theory analysis have been introduced by several researchers (Glaser, 1978; Rennie et al., 1988; Charmaz, 2000; Strauss \& Corbin, 1990, 1998; see McLeod, 2003), who have modified the original grounded theory procedures in several respects. This has led some observers to use the term "grounded theory methodology" instead of referring to one grounded theory method (Mey \& Mruck, 2007).

Allen (2010) argues that whereas Glaser and Strauss (1967) employ a more formal and classic form of grounded theory in which the emergence of a theory is considered to be as important as verification of the theory, Strauss and Corbin (1998) provide a set of procedures embedded in the coding paradigm that they claim validates the codes and categories. Meanwhile, Charmaz (2006, in Allen, 2010, p. 7) articulates a more constructivist view and suggests that "the researchers are not separate from the theories but construct them through their interactions with people, places and research perspectives." In addition, Rennie (2000) emphasizes the interpretive aspect of the grounded theory method, asserting that it is methodologically hermeneutical (see also Locke, 2001). Clarke (2005) suggests a more postmodern view of grounded theory, introducing an innovative method that uses situational maps to analyze the data. For a general overview, see Bryant and Charmaz (2007) and Morse et al. (2009).

Despite these differences, in all of the versions, the researcher intends to generate theory through the exploratory, interested and open-minded examina- 
tion of material rather than using that material to verify an existing theory (McLeod, 2001; Rennie, 1994; Rennie et al., 1988). In addition, all of the versions entail a family of procedures. Specifically, all involve the constant comparison method. This means that new codes evolve and are compared to codes already conceptualized during the research project. Throughout this coding activity, the researcher reflects on his or her own background and the ideas he or she contributes to the research and formulates preliminary thoughts about the meanings of the texts under analysis, considering possible connections between codes, etc. The text as a whole is used to inform the meaning of its parts and vice ver$\mathrm{sa}$, creating a hermeneutic circle that eventuates in the creation of concepts, which are represented as codes. This is accomplished through the procedures described as selective, axial and theoretical coding, in which the researchers try to create connections among the codes and connect the codes with existing theories. This process yields a set of core codes or an emerging grounded theory that explains the phenomenon of interest as a whole and in its particulars.

These explicit steps for applying grounded theory method can also be described in more theoretical terms as eductive, ${ }^{3}$ abductive, deductive and inductive processes. Although the method is commonly described as involving induction, or bottom-up analysis, it has been argued that it entails more than induction. During the inductive collection of data, researchers may discover new meaning that is drawn out, or educed, from the data. The educed meaning is represented as a concept, which is turned into a hypothesis or abduction-an initial prediction of how the phenomenon might be described (see Salvatore \& Valsiner, 2010). We proceed to deduce that the additional text may provide evidence in support of the hypothesis, which constitutes an inductive analysis of the text. During this induction, new meaning may be educed, necessitating a new round of the logical operations. This cycle continues until no new meanings are educed from the corpus of texts, at which point the analyst may consider the categorization of meanings educed to be saturated (Rennie, 2012; see also Rennie \& Fergus, 2006, on embodied categorizing). ${ }^{4}$

\section{The skill of the researcher}

An important aspect of the grounded theory approach is the attitude of the researcher. The approach requires a curious and passionate researcher

\footnotetext{
${ }^{3}$ Eduction is defined as "The action of drawing forth, eliciting, or developing from a state of latent, rudimentary, or potential existence; the action of educing (principles, results of calculation) from the data" (Oxford English Dictionary in Rennie, 2012, p. 388).

${ }^{4}$ For a more detailed discussion, see Rennie's paper (2012) on Methodical Hermeneutics.
}

who is primarily interested in understanding a particular phenomenon and is also able to apply specific research procedures. The goal of the researcher is to examine the data thoroughly, and it is therefore important to be able to be sensitive to the different meanings the data may suggest. As Rennie et al. (1988, p. 141) stress, "the grounded approach forces investigators to stay close to their data, so that somewhat different theories arising from the same data are the result of the different analysts emphasizing different aspects of them." Additionally, for the researcher to be both immersed in the data and able to act with theoretical sensitivity, it is important for him or her to be able to reflect on his or her own biases and assumptions (McLeod, 2011).

Another important characteristic of the grounded theory approach, which some authors stress more strictly than others, is that the researcher should not review the literature before collecting the data (McLeod, 2011). Proponents of this practice believe that the research process should begin with the acceptance of uncertainty and move gradually towards the development of a differentiated theory (Elliott, Slatick \& Urman, 2001). It is important to approach the phenomenon with no prior specific knowledge and to explore its nature during the process of analysis without being influenced by previous theories and assumptions and without presuming the outcome of the study. Strauss and Corbin (1990), for instance, assert that a literature review is unnecessary because the analysis of an effective researcher will reveal previously unthought of categories. In addition, the absence of a specific research question is important; the researcher should only have an abstract idea of the phenomenon he is investigating and remain open to exploration (Glaser, 1992).

The application of grounded theory is inspired by the everyday language of the participants of the study, is influenced by the theoretical and professional community to which the researcher belongs and depends on the analyst's interpretation of the participants' responses (McLeod, 2011). The researcher's representation of the meanings of the text in terms of a set of codes is a complex, creative process. Users of the method have mentioned that they have become so immersed in the phenomenon under investigation that it has become their life. Therefore, good interpretation involves "living inside and outside of the experience and monitoring of the degree of fit between the two aspects" (Rennie, 2000, p. 487).

\section{Method}

\section{Data collection and theoretical sampling}

Having presented a broad overview of grounded theory method and the role of the researcher, we now proceed to describe a set of guidelines and specific steps for applying the method. In what follows, we will describe the key concepts of the method, namely, theoretical sampling, constant comparative data analysis, 
diagramming, memo writing, and conceptualization of a core code, to explain how users of the method collect data and code them to the point of saturation.

Once the researcher identifies a research question that is broad and open-ended, data are collected that may contribute to the exploration of the phenomenon. Levitt (in prep.) states that differences among participants are seen as strength in grounded theory analysis because these differences enrich and broaden the theory. A diverse sample is able to represent existing variation in people's perceptiveness (Higginbottom, 2004). However, that which is sampled must not exceed the boundary of the specific research question.

First, participants are chosen who promise to maximize the chances that aspects of the phenomenon will emerge clearly in the initial stages (Rennie et al., 1988). Thus, data collection begins with selective sampling, or identification of the population and its characteristics prior to data collection (Schatzman \& Strauss, 1973, in Draucker, Martsolf, Ross, \& Rusk, 2007). In this case, one knows how sampling needs to begin but not what the final results will be (Coyne, 1997). As the study progresses, the researcher should shift to theoretical sampling when concepts and descriptive categories begin to emerge (Draucker et al., 2007).

Theoretical sampling is a central feature of grounded theory method and can be defined as an approach "in which new observations are selected to pursue analytically relevant distinctions rather to establish the frequency of phenomena" (Emerson, 1981, in Higginbottom, 2004, p. 9). Theoretical sampling is considered crucial to the development of a dense theory (Fassinger, 2005). Procedurally, the researcher compares and contrasts the available data to decide what data would be useful to collect next. Schwandt (2001, p. 111) mentions that "theoretical sampling means that the sampling of additional incidents, events, activities, population, and so on is directed by the evolving theoretical constructs." When conducting theoretical sampling, the researcher collects and analyzes his or her data simultaneously and then decides what data to collect next.

Theoretical sampling involves testing, elaborating and refining a code and then sampling in a way that promises to develop the categories and their relationships and interrelationships (Coyne, 1997). A researcher using the theoretical sampling method can enhance the process by being flexible enough to change interview styles between participants and add diversity to the sample. It is also possible to ask key participants to provide more information for essential categories (Glaser, 1978). Some studies also mention that authors who use theoretical sampling tend to modify their interview questions as the study progresses (Draucker et al., 2007).

Clearly, theoretical sampling is a complex process that is dependent on the skills of the qualitative researcher. Therefore, according to Mason (2002), the researcher needs to be skilled in putting people at their ease, listening and reflecting and monitoring and structuring the flow of the interview. ${ }^{5}$

Furthermore, sample sizes are usually small by conventional research standards. Small samples are more conducive to thoroughly reviewing and capturing the richness of the data (Miles \& Huberman, 1994). Typically, grounded theory research is carried out on samples of between 8 and 20 participants (McLeod, 2011). In theoretical sampling, data collection continues until the investigator judges that there are no more new emergent themes or concepts to be discovered. At this point, the categories are considered saturated because the constant comparative procedure has led to the conclusion that no new information is forthcoming (Tuckett, 2004). A more detailed explanation of the process of constant comparison will be given below in the description of the analysis.

\section{Data analysis}

The data analysis method resembles theoretical sampling because, as was indicated above, data gathering and coding occur simultaneously. The researcher, after collecting the initial sample, begins the process of conceptualizing descriptive categories. Glaser (1978) suggests that the material should be analyzed line by line, whereas Rennie et al. (1988; see also Rennie, 2012) argue that the method is expedited when the text is divided into meaning units. They define meaning units as passages of text that typically, but not always, "contain" a single idea. The meaning units may be short (e.g., a phrase), as in the lineby-line coding used by Charmaz (2006), or as long as a paragraph, a page, or more (see Rennie, 2006).

The style in which researchers conduct analysis in practice currently varies greatly. Some keep analytic notes; others prefer to condense the content of meaning units on cards; and still others use Microsoft Word to document their categories or even use a computer software that was designed to assist the qualitative research process, for example, Nvivo (Gibbs, 2002) or Atlas.ti (Gibbs, 2007; see also Muhr, 1994). The latter is designed to accommodate the grounded theory method and can be used for various types of text, audio and video analyses. Once the data are broken into meaning units, the researcher educes their meanings and represents each meaning as a descriptive code. For the initial stages of the study, it is recommended that the codes remain close to the language of the informants to promote grounding in the data. This process is thus open to the adoption in $v i$ vo codes or pithy terms and phrases used by the par-

\footnotetext{
${ }^{5}$ Occasionally, theoretical sampling is not possible. This is the case when the researcher is presented with a "found" sample intact, acquires a sample through a "snowball" approach or has access to a data bank. It is generally agreed that use of such sampling, while not ideal, is acceptable if the researcher recognizes its limitations.
} 
ticipants (see above; see also Strauss and Corbin, 1998). Each code is filed with the given meaning unit assigned to it, accompanied, perhaps, by a condensation of the meaning unit if such condensations provide convenient overviews of the meaning units assigned to the codes. This process of categorization is called open coding (Elliott et al., 2001). Open coding is considered the heart of the method, and its aim is to generate as many codes as is deemed appropriate for each meaning unit in the text. Strauss and Corbin (1990, p. 61, in McLeod, 2011) define open coding as the process of "breaking down, examining, comparing, conceptualizing and categorizing data." The same authors suggest that the codes should refer to activities or processes and not to static entities, but this admonition is not set in stone.

In the following example, we present a text segment derived from a transcript of an interview study titled Exploring the process of therapeutic change in systemic family therapy (Dourdouma, in prep.). The segment originated in an interview (conducted by the first author of this paper) with a female client in her forties. She is describing her experience of internal change after having completed her therapy:

Interviewer (repeats and summarizes what the client has just said in her own words): So the changes had to do with you, with your internal life?

Client: Personally, to me, yes [...] the changes had to do with my internal life....also very much with the expression of my feelings, because that is really, really important [...] emmm, the fact that it (the emotion) can come to the surface too, that it can be externalized [...] because once I was a very introversive person, so I think that if something changed, it is through self-awareness [...] mmm I think I changed towards me, not me towards others that much.

Interviewer: Yes, I have understood that, I think that is very clear to you.

Client: Yes, that is clear

Interviewer: But what exactly has changed, what has changed towards yourself? [...] You already mentioned some things, for example that you are more open.

Client: Yes, I am more open, I certainly have more selfesteem, which I didn't have in the past, I appreciate myself differently, I am more assertive, whereas in the past I was not [...] I am less tolerant [...] There are people that are in therapy in order to become more tolerant because they are not, but I became less [...] I mean that I became less tolerant with things that I don't like, with things that are not in my interests [...] I distanced myself. You know, I don't want to waste my time anymore, I want my time to be qualitative and substantial.

Interviewer: So we talk about internal and substantial changes, which may, as you say, not influence your behavior that much, but they have certainly influenced your life, your relationships with other people.

Client: My relationship with other people is on a second level. The changes influenced the relationship with myself and then with others. That's why I am telling you that I didn't change my behavior. I think that my behavior didn't change. This is the way I feel, I think I am the same person. I think that because of the fact that the relationship with myself changed, the place where I have placed myself changed [...] I think that this has consequences $[\ldots .$.$] certainly it has consequences.$

To model open coding, we present the following codes, which we conceptualized for the above meaning unit. The coding process of the study presented above was discussed and reviewed by a supervisor (the second author of this paper) in order to reach consensus (Guba \& Lincoln, 1989) and ensure the trustworthiness of the results. To represent our results, we will use the following sequential labeling: Codes (the result of the open coding phase, low in abstraction, close to the actual words of the interviewee), second-level codes (higher order codes created by subsuming codes), even higher order codes representing groups of first- and/or second-level codes and core codes (the primary conceptual results, most prominent and general aspects of the investigated phenomenon). For more detailed information about why we chose this terminology, please refer to footnote 3 . The following codes depict the concept-themes derived from the client's experience of internal change:

- Code 1: Through self-awareness, the emotion came to the surface. towards myself, not to others.

- Code 2: I changed towards myself, not to others.

- Code 3: I became more assertive (less tolerant, which was good and in my interest).

- Code 4: Becoming more focused on what I want, not wasting myself anymore.

- Code 5: Behavior does not change, but the way I understand/relate to myself does.

It is important to carry out the analytic process of open coding with what Strauss and Corbin (1990) call theoretical sensitivity (see also Glaser, 1978). This means that the researcher must challenge his own preconceptions and assumptions and delve into the experience of the participant. Wertz (1983, in Elliott et al., 2001) agrees and refers to this process as psychological reflection, or immersing oneself in the informant's experience. The researcher accomplishes this through the empathic process of "entering and dwelling," separating his or her assumptions from the meanings that emerge from the data. As mentioned in the introduction, Rennie and Fergus (2006) describe this process as embodied categorizing. During this process, the researcher, who has just begun to interpret and understand the text, feels its meaning intuitively. This understanding is arrived at through one's intellectual capacities and through the memories, images and associations that are stored and actualized in one's body.

In the process of analyzing, the researcher employs another intuitive technique: the constant comparative method. This method consists of a constant comparison of the categories until the meanings of 
Table 1. Axial coding that represents main categories (I, II), second level codes (A, B, C) and low abstract codes $(1,2,3,4)$ from a grounded theory study of clients' experience of change

I. Getting in touch with my Inner Self

A. Focusing on my needs

1. I stopped living the life of others and I saw my own deep needs of partnership

2. I stopped wasting myself and my time on things I was not interested in

3. Becoming more focused on what I want

4. I realized I should do things for me and not neglect myself

B. Putting my own boundaries

1. I learned to put my own rules for myself

2. I learned to say "NO" and that is relieving

3. I realized I need to put boundaries

C. Allow differentiation of myself

1. I was afraid to change my life and I let things the way they were

2. It was important to be different from the mass

3. Allowing myself to change

II. Relating to the others

A. Improving existing relationships

1. I reformed the relationship with my parents

2. I stopped being afraid and this improved my communication with others

B. Being more attuned to others

1. Understanding that people have different timings

2. Giving value on my partners' needs

3. Changing my behavior towards other people

all of the categories have been compared and contrasted with each other (McLeod, 2011). This approach encourages the analyst to constantly observe the similarities and differences among the categories, and it allows the diversity and the complexity of the data to be explored (Elliott et al., 2001). The researcher compares his previous understanding with the new discoveries, becoming increasingly immersed in the data. According to Rennie (2006; Rennie et al., 1988), during the process of constant comparison, the researcher begins to categorize data with the intention of creating a theory. Thus, the development of a new theory, which is the central aim of grounded theory method, occurs through the constant comparison of the data collected via theoretical sampling (Coyne, 1997).

In the following example, we present the comparison of the codes and the formulation of the more abstract, second-level code. The following three (low abstract) codes were compared and contrasted and then combined into one second-level code as follows:

- Code 1: Change happened through pain and personal work.

- Code 2: Change through therapy comes with time and hard work on the client's part.

- Code 3: There is no magic recipe for bringing about change; it requires time and hard work

After comparing the three codes, one second-level code emerges that includes the meanings of all three codes:

- Second-level code: Pain, time and hard work bring about change.
As the analysis progresses, the analyst begins to develop a focus, which is expressed through theoretical sampling and selective coding. ${ }^{6}$ During this process, the previously identified categories are used for more deductive coding. Nevertheless, the researcher remains open to discovering new emerging categories. Muckel (2007) highlights that this openness to new categories expresses the researcher's openness to a change of direction. Even when one believes that he or she has reached the end of an analysis, new, unexpected information may appear that suggests a new path. Flexibility is a key characteristic of Grounded Theory and distinguishes it from other qualitative analysis procedures (such as Mayring's [2003] qualitative content analysis).

The next step in grounded theory analysis is axial coding, in which connections are created among the codes. To complete this task, the researcher identifies and observes the connections between the categories and organizes the data into a general formal framework according to a previous or emerging general understanding of the phenomenon (Elliott et al., 2001). ${ }^{7}$ Elliott, Slatick and Urman (2001), note that axial coding plays an important role because it reduces the complexity of the analysis and produces a

\footnotetext{
${ }^{6}$ However, consider the differences among grounded theory methods that have emerged over time, described in the introduction of this paper.

${ }^{7}$ In Strauss and Corbin's work (1990), axial coding is a fundamental part of their coding paradigm. In Glaser's work (1978), this step includes the utilization of coding families for sensitizing concepts and overlaps with the next step, theoretical coding.
} 


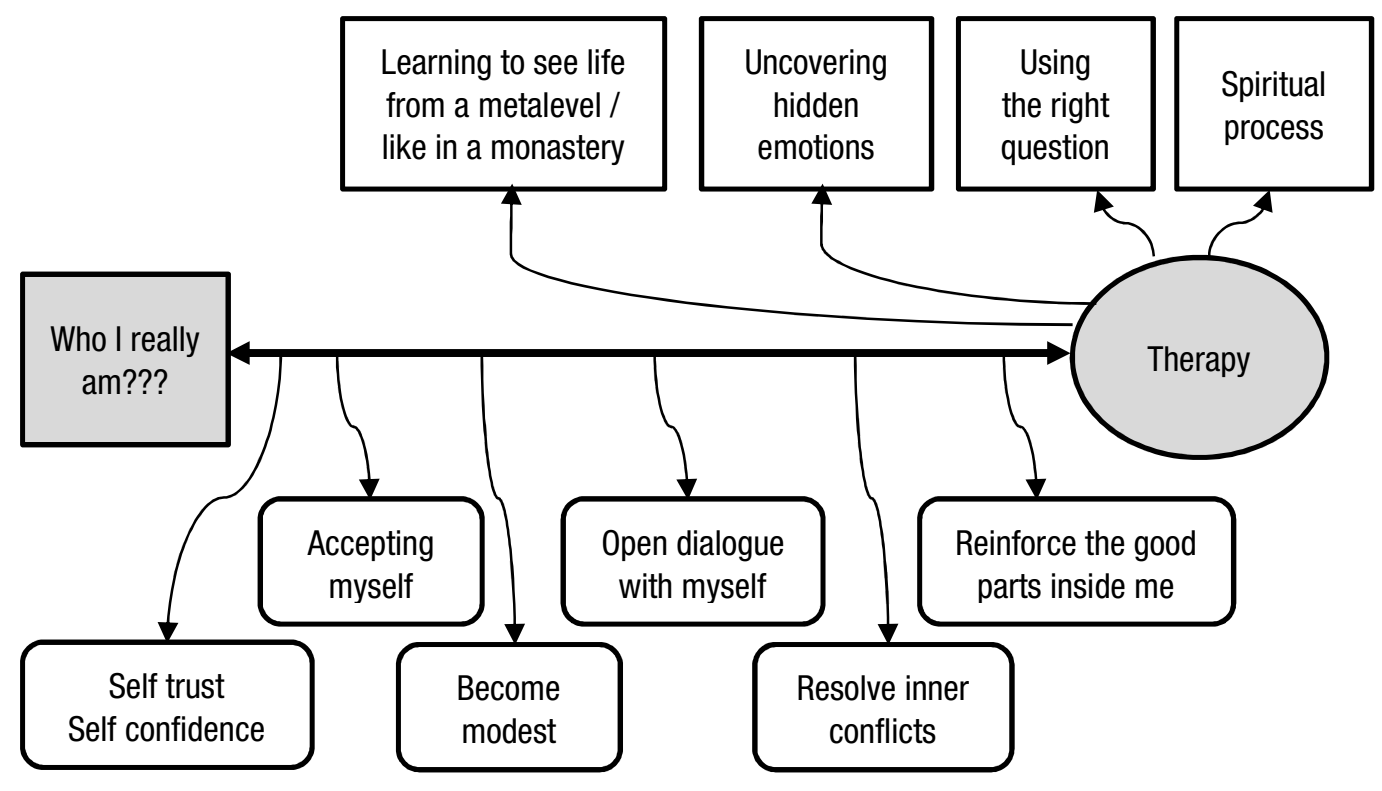

Figure 1. Graphic mirroring a male client's experience of systemic family therapy.

general narrative structure.

Table 1 provides an example of axial coding that was performed for a grounded theory analysis of data from our study of clients who had completed systemic family therapy. Clients' description of their experiences of change after completing therapy created the following second-level codes: (I) Getting in touch with my Inner Self; (II) Relating to others.

Table 1 shows that the second-level categories subsume lower-level codes. ${ }^{8}$ In particular, clients referred to the process of "Getting in touch with my Inner Self," which is closely related to "Focusing on my needs." Furthermore, the latter process includes the processes of "Ceasing to live other people's lives and seeing my own deep needs for partnership," "Not wasting myself and my life in uninteresting things" and "Realizing that I should do things for me and not neglect myself." In addition, two other aspects of "Getting in touch with my Inner Self" included "Establishing my own boundaries" and "Allowing myself to differentiate." These processes also included subcategories, such as "Learning to establish my own rules." "Learning to say 'No'," "Allowing myself to change," etc.

The next second-level code described by clients was the process of "Relating to others," which included the following two processes: "Improving existing relationships" and "Being more attuned to others." Clients improved their "Relating to others" process by "Reforming relationships," "Eliminating fear

\footnotetext{
${ }^{3}$ Researchers use different words for this depending on the grounded theory tradition to which they ascribe. For some, higher-order categories subsume lower-order categories. For others, it is the properties of the higher-order categories that are subsumed.
}

to improve communication with others," "Understanding the differences in other people's timing," "Recognizing the value of other people's needs" and "Changing my behavior towards others."

The above example demonstrates that axial coding is a helpful process for the researcher because it emphasizes specific aspects and meanings and enhances the narrative structure of the analysis. As the data analysis progresses, fewer new descriptive categories emerge, and the analysis eventually reaches a point at which the codes (or categories; see footnote 3 for further information about these terms) are saturated (Rennie \& Brewer, 1987). Saturation of the data means that no new meaning can be educed from new data that has not already been accounted for by the codes/categories previously conceptualized. Therefore, no new data need to be sought. The researcher then observes and identifies interrelationships between the codes and combines the codes into common themes. In other words, the initial codes are grouped, based on commonalities, into second-level codes.

Helpful tools for the data analysis process. From the beginning of the analysis process, the researcher is forming different hypotheses, observations, connections and associations regarding the codes that influence how the codes are formed and labeled. To make this (abductive-inductive) process transparent, the researcher should record these ideas and thoughts. The researcher's memos can be written accounts but can also include graphics. The type of graphic used depends on the researcher's preference; they may be pencil drawings on notepaper, PowerPoint slides saved on the computer or simply mental images inspired by metaphors. However the researcher documents his or her growing understanding, this 


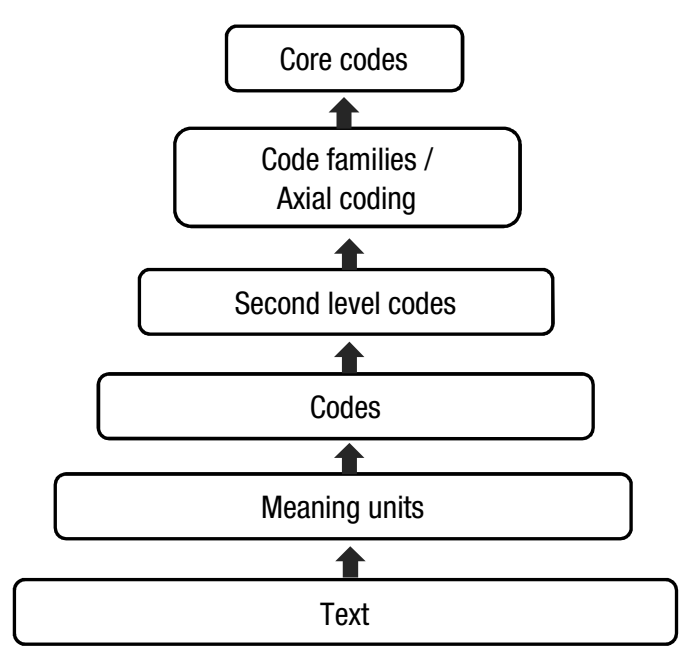

Figure 2. Main steps of grounded theory analysis.

documentation is considered the first step of conceptualization, and graphics typically accompany the qualitative analysis. Good (comprehensive and expressive) graphics mirror the researcher's understanding and his or her grounding in the categorizations, which in turn mirror the experience of the client.

For example, for the purposes of the study mentioned above (see Dourdouma, 2012b), the first author conducted an interview with a 38-year-old man who was asked about his experiences with systemic family therapy in Greece. The interview was focused on the process of change and was based on the Change interview (Elliott, 1996). We analyzed the interview, applied open coding and developed specific ideas about how these codes were connected. Figure 1 displays our understanding of this client's experience and presents the impressions created and the understanding reached in the process of the interview.

A good graphic (especially one that appears at the end of the analysis) that represents the main findings of a study should be as self-explanatory as possible. However, psychotherapeutic processes are complex phenomena, and the graphics representing them may therefore require a brief explanation. The graphic above depicts the therapeutic process of change of a client whose basic concern was to discover "Who he really is" (exact quotation from the client). Through his therapeutic journey, he seems to have gained selftrust and self-confidence, accepted himself as he is, resolved his inner conflicts, become modest and begun to hold an open dialogue with himself (these processes are all grounded in the data and represent codes). The client described therapy as a spiritual process that helped him to see life from a meta-level (the relevant code is "To see my life from a distance, like when living in a monastery"). He added that the therapist helped him to uncover hidden emotions by asking the right questions. In addition to listing the codes, the graphic (with its lines and arrangement of graphical items) condenses the individual codes into a concept. A graphic can include a sequence (first, next and last), causal links (if-then, because of) or suggest which codes are more closely related than others. The graphic above shows the client's reflections on therapy as a process. Beginning with "Therapy," the graphic explains how the client defines psychotherapy (uncovering hidden emotions, etc.). Therapy is here opposed to the "Who I really am" item. This reflects the client's struggle to discover who he is, what therapy is and how he can make use of this well-defined concept of therapy. The intermediate codes that connect the left and right side organize the client's experience of psychotherapy sequentially: By reinforcing his positive traits, he came to experience self-trust and developed more confidence in who he really was.

As this discussion demonstrates, memos and diagrams/graphics can help the researcher construct an interpretation of the material (McLeod, 2003). They may also help researchers "bracket-off" their ideas or assumptions to prevent them from interfering in the analysis process (Strauss \& Corbin, 1990).

Reaching the end of a grounded theory analysis: Aiming at a core code. At the end of the analysis, the researcher conceptualizes the most central code. The core code is related to the other codes (and the second-level codes); it colligates or expresses in a single code the fundamental principle of the phenomenon under exploration. The core code should encompass the whole structure of the codes, including the relationships among them and among the codes and the data (Rennie \& Brewer, 1987). Strauss and Corbin (1998) argue that the core code must be related to all of the other codes, appear frequently in the data and that its name should be abstract enough to generate a preliminary theory. In addition, the main code or codes should be theoretically related to the findings and theories of other studies (McLeod, 2011). The main code or codes that emerge conceptualize the data and capture their essential meanings. However, although arriving at a core code can be a difficult process, it is a meaningful process that contributes to the coherence and analytic depth of the study (McLeod, 2003). ${ }^{9}$

Figure 2 conveys our understanding of grounded theory analysis and presents the basic steps that researchers follow to arrive at the core code. The figure is constructed linearly to facilitate easy recognition of the steps. However, all of the sequenced steps are actually connected with each other recursively in a manner reminiscent of the hermeneutic circle; the core codes, relations among codes and among groups of

\footnotetext{
${ }^{9}$ For example, in the study (Dourdouma, 2012b) we refer to in the previous pages, the following preliminary core category has been identified: "The experience of therapeutic change, within the secure frame of therapy, is a process of deconstructing and reconstructing the house you live in: Yourself'.
} 
codes, etc. always refer to and build upon each other.

In the final sentences, we intentionally refer to the main code or "codes," which highlights another important modification in contemporary grounded theory analyses. Although the core code (or the code that organizes the resulting grounded theory) is the desired result in classic grounded theory designs, often researchers represent the results in a group of main codes. This may be because grounded theory techniques are sometimes embedded in research designs whose scope extends beyond generating one hypothesis/theory generating. In this case, some phenomena may require the interplay of three or four codes, rather than one overarching conceptualization (or one core code), to capture their complexity. In whatever way the results are made to best represent a phenomenon, the researcher must engage in a complex process at the end of the analysis. It is the researcher's primary task to first collect codes that are as differentiated as possible and then to sort them, become immersed in the data, rediscover the central themes and then, finally, to condense the work of one or two years into a simple, comprehensible concept. Whether the concept is expressed in the form of one grounded theoretical sentence, one core code or a set of interconnected main codes is therefore a secondary consideration.

Before concluding, it is necessary to mention that, according to Glaser (1998), a substantial grounded theory should be judged according to four components: fit, relevance, workability and modifiability. Glaser considers fit to be an aspect of validity that shows how successfully the concepts match the incidents they represent. Relevance describes whether the concepts are related to the actual phenomenon and whether the study addresses the real concerns of the participants. Workability refers to whether a theory really works. A theory is said to work when it explains how a main concern is resolved through variation. Lastly, modifiability means that the theory can be modified when new data are compared to the existing data. Importantly, a grounded theory is never right or wrong. Instead, it has more or less fit, relevance, workability and modifiability (Glaser, 1998).

\section{Conclusions and reflections on grounded theory analysis}

The process of grounded theory analysis can be described as an activity in which the data are broken up through the process of categorization and are reassembled through the process of theory construction (McLeod, 2003). The former process has been criticized by some authors. For instance, Thomas and Games (2006) claim that this method, which includes dividing the text (through axial coding, codes, second-level codes, etc.), seeks to impose a specific type of thinking that reduces the role of the original voice, the narratives and even clear accounts by researchers themselves because it over-emphasizes methodology and techniques. The same authors argue that using the method entails a denial of acquired knowledge and a rejection of simple understanding.

We see grounded theory method as a way to make sense of the complex phenomena and processes constituting an individual's experiences, which are often private in nature. Grounded theory analysis is a qualitative method that facilitates researchers' explorations of a variety of phenomena. Because its aim is to generate new theory, it is used in fields where little is known or in fields in which knowledge about a social phenomenon already exists but could be further enhanced. It involves the researcher in the creative activity of theory building (Silverman \& Marvasti, 2008).

Whether or not the method enables the conceptualization of what Glaser and Strauss (1967) called formal theory, as opposed to substantive theory that is localized in particular contexts, is a moot point. In recent years, researchers have addressed this methodological issue. Mörtl, Gelo, and Pokorny (in press), argue that the original intent of grounded theory could be interpreted as a post-positivist method for approaching an objective truth (represented by one formal theory). Grounded theory methodology has undergone constructive and hermeneutical revisions (see also Charmaz, 2006; Rennie, 2012) and no longer claims to reach one explanatory theory.

Breaking the text into smaller units and labeling them is a process that requires the researcher to be truly immersed in the data. The method's respect for the data and the possibility it creates for exploring the material with openness, untrammeled by previous knowledge, is what makes it a way to facilitate new discoveries. Therefore, McLeod (2003, p. 143) characterizes it as an a-theoretical and a-historical method "which produces pragmatic frameworks for understanding categories and procedural models that are effective in specific contexts." We complement these remarks by underlining one more key aspect of grounded theory: the researcher. Grounded theory is more than a method or a methodology. It is a research attitude (Denzin \& Lincoln, 2000) localized in a person and affected by all of his or her personal potential and limitations. However, we also want to critically reflect upon this point: While we agree with Denzin \& Lincoln's statement, it should be noted that in the last 20 years, grounded theory has been used as a label not only for the application of the method itself but for a wide variety of qualitative procedures. Suddaby (cited in the introduction to the grounded theory reader by Mey \& Mruck, 2007, p. 14) says pointedly: "I note, with some concern, that 'grounded theory' is often used as rhetorical sleight of hand by authors who are unfamiliar with qualitative research and who wish to avoid close description or illumination of their methods."

In conclusion, the manner in which a grounded theory study is carried out depends on the unique contributions of the researcher. Thus, we suggest that interested readers experiment with this exciting 
method; if it suits their basic attitudes and understanding of science, they will find a way to fit the method's procedures to their needs and the needs of the given phenomenon that they seek to explore.

\section{References}

Allen, L. M. (2010). A critique of four grounded theory texts. The Qualitative Report, 15(6), 1606-1620.

Bryant, A., \& Charmaz, K., (Eds.). (2007). The Sage handbook of grounded theory. London: Sage.

Charmaz, K. (2000). Grounded theory: Objectivist and constructivist methods. In N. K. Denzin and Y. S. Lincoln (Eds.), Handbook of qualitative research (2nd ed.). Thousand Oaks, CA: Sage.

Charmaz, K. (2006). Constructing grounded theory: A practical guide through qualitative analysis. London: Sage.

Clarke, A. (2005). Situational analysis: Grounded theory after the postmodern turn. Thousand Oaks, CA: Sage.

Corbin, J. M. (1998). Alternative interpretations. Valid or not? Theory and Psychology, 8(1), 121-128. doi:10.1177/ 0959354398081007

Corbin, J., \& Strauss, A. (2008). Basics of qualitative research. Techniques to developing grounded theory (3rd ed.). Los Angeles, CA: Sage.

Coyne, I. T. (1997). Sampling in qualitative research: Purposeful and theoretical sampling; merging or clear boundaries? Journal of Advanced Nursing, 26, 623-630. doi:10.1046/j.1365-2648.1997.t01-25-00999.x

Denzin, N. K., \& Lincoln, Y. S. (Eds.). (2000). Handbook of qualitative research (2nd ed.). Thousand Oaks, CA: Sage.

Dourdouma, A. (2012a). Exploring the process of therapeutic change in systemic family therapy: A qualitative study based on clients' perceptions. Paper presented at the 3rd Joint Meeting of Society for Psychotherapy Research European and UK Chapters, Porto, Portugal.

Dourdouma, A. (2012b) Exploring the process of therapeutic change in systemic family therapy: A qualitative study based on clients' perceptions. Doctoral Thesis. Sigmund Freud University Vienna.

Draucker, C. B., Martsolf, D. S., Ross, R., \& Rusk, T. B. (2007). Theoretical sampling and category development in grounded theory. Qualitative Health Research, 17(8), 1137-1148. doi:10.1177/1049732307308450

Elliott, R. (1996). Client change interview schedule. Unpublished research instrument, Department of Psychology, University of Toledo.

Elliott, R., Slatick, E., \& Urman, M. (2001). Qualitative change process research on psychotherapy: Alternative strategies. In J. Frommer \& D. L. Rennie, (Eds.), Qualitative psychotherapy research: Methods and methodology. Lengerich/Berlin/Riga/ Rome/Wien/Zagreb: Pabst Science Publishers.

Fassinger, R. E. (2005). Paradigms, praxis, problems, and promise: Grounded theory in counseling psychology research. Journal of Counselling Psychology, 52(2), 156-166. doi:10.1037/0022-0167.52.2.156

Gibbs, G. R. (2002). Qualitative data analysis: Explorations with NVivo. Buckingham: Open University Press.

Gibbs, G. R. (2007). Analyzing qualitative data. London: Sage.

Glaser, B. G. (1978). Theoretical sensitivity: Advances in the methodology of grounded theory. Mill Valley, CA: The Sociology Press.

Glaser, B. G. (1992). Emergence versus forcing: Basics of grounded theory analysis. Mill Valley, CA: Sociology Press.

Glaser, B. G. (1998). Doing grounded theory: Issues and discus- sions. Mill Valley, CA: Sociology Press.

Glaser, B. G. \& Strauss, A. (1967). The discovery of grounded theory: Strategies for qualitative research. Chicago, IL: Aldine.

Guba, E. G. \& Lincoln, Y. S. (1985). Fourth generation evaluation. Newbury Park, CA: Sage.

Higginbottom, G. M. A. (2004). Sampling issues in qualitative research. Nurse Researcher, 12(1), 7-19.

Legewie, H. (2004). "Research is Hard Work, it's Always a bit Suffering. Therefore on the Other Side it Should be Fun." Anselm Strauss in Conversation With Heiner Legewie and Barbara Schervier-Legewie. Appendix: Anselm Strauss as a Research Supervisor. A Memo [9 paragraphs]. Forum Qualitative Sozialforschung/Forum: Qualitative Social Research, 5(3), Art. 22, http://nbn- resolving.de/urn:nbn:de:0114fqs0403222.

Levitt, H. (in prep.). Study-driven guidelines for designing and evaluating grounded theory research: A constructivistsocial justice approach. In O. Gelo, A. Pritz \& B. Rieken (Eds.), Psychotherapy research: General issues, process and outcome. Vienna/New York: Springer.

Locke, K. (2001). Grounded theory in management research. London: Thousand Oaks.

Mason, J. (2002). Qualitative researching. London: Sage.

Mayring, P. (2003). Qualitative inhaltsanalyse: Grundlagen und techniken [Qualitative content analysis: Principles and techniques]. Weinheim, Basel: Beltz Verlag.

McLeod, J. (2001). Qualitative research in counseling and psychotherapy. London: Sage.

McLeod, J. (2003). Doing counseling research. London: Sage.

McLeod, J. (2011). Qualitative research in counseling and psychotherapy (2nd ed.). London: Sage.

Mey, G., \& Mruck K. (2007). Grounded theory methodologie: Bemerkungen zu einem prominenten Forschungsstil [Grounded theory methodology: Remarks to a prominent research style]. Historical Social Research/Historische Sozialforschung, Supplement No. 19, 11-43.

Miles, M. \& Huberman, A. (1994). An expanded source book: Qualitative data analysis (2nd ed.). London: Sage.

Mörtl, K., Gelo, O., \& Pokorny, D. (in press). Qualitative process research methods. In O. Gelo, A. Pritz \& B. Rieken B. (Eds.), Psychotherapy research: General issues, process and outcome. Vienna/New York: Springer.

Morse, J. M., Stern, P. N., Corbin, J. M., Bowers, B., \& Clarke, A. E. (2009). Developing grounded theory: The second generation. Walnut Creek, CA: University of Arizona Press.

Muckel, P. (2007). Die Entwicklung von Kategorien mit der Methode der Grounded Theory [The development of categories using the method og Grounded Theory]. Historical Social Research/Historische Sozialforschung, Supplement No. 19, 211-231.

Muhr, T. (1994). Atlas.ti computer aided text interpretation and theory building. User's manual. Berlin: Scientific Software Development.

Rennie, D. L. (1994). Storytelling in psychotherapy: The client's subjective experience. Psychotherapy, 31(2), 234-243. doi: $10.1037 / \mathrm{h} 0090224$

Rennie, D. L. (1998a). Grounded theory methodology: The pressing need for a coherent logic of justification. Theory \& Psychology, 8(1), 101-119. doi:10.1177/0959354398081006

Rennie, D. L. (1998b). Reply to Corbin: From one interpreter to another. Theory \& Psychology, 8(1), 129-135. doi: $10.1177 / 0959354398081008$

Rennie, D. L. (2000). Grounded theory methodology as methodical hermeneutics: Reconciling realism and relativism. Theory \& Psychology, 10(4), 481-502. doi:10.1177/ 0959354300104003

Rennie, D. L. (2006). The grounded theory method: Application of a variant of the procedure of constant comparative analysis to psychotherapy research. In C. T. Fischer (Ed.), 
Qualitative research methods for psychologists: Introduction to empirical studies (pp. 59-78). Boston, MA: Elsevier.

Rennie, D. L. (2012). Qualitative research as methodical hermeneutics. Psychological Methods, 17(3), 385-398. doi:10.1037/a0029250

Rennie, D. L. \& Brewer, L. (1987). A grounded theory of thesis blocking. Teaching of Psychology, 14, 10-16.

Rennie, D. L. \& Fergus, K. (2006). Embodied categorizing in the grounded theory method: Methodical hermeneutics in action. Theory \& Psychology, 16(4), 483-503. doi:10.1177/ 0959354306066202

Rennie, D. L., Phillips, J. R., \& Quartaro, G. K. (1988). Grounded theory: A promising approach to conceptualizing in psychology? Canadian Psychology, 29(2). 139-150. doi:10.1037/h0079765

Salvatore, S., \& Valsiner, J. (2010). Between the general and the unique: Overcoming the nomothetic versus idiographic opposition. Theory \& Psychology, 20(6), 817-833. doi: $10.1177 / 0959354310381156$

Schwandt, T. A. (2001). Dictionary of qualitative inquiry. (2nd ed.). Thousand Oaks, CA: Sage.

Silverman, D., \& Marvasti, A. (2008). Doing qualitative research: A comprehensive guide. London: Sage

Strauss, A. L. (1987). Qualitative analysis for social scientists.
New York: Cambridge University Press.

Strauss, A., \& Corbin, J. (1990). Basics of qualitative research: Grounded theory procedures and techniques. Newbury Park, CA: Sage.

Strauss, A., \& Corbin, J. (1998). Basics of qualitative research: Techniques and procedures for developing grounded theory (2nd ed.). Thousand Oaks, CA: Sage.

Strübing, J. (2007). Glaser vs. Strauss? Zur methodologischen und methodischen Substanz einer Unterscheidung zweier Varianten von Grounded Theory [Glaser vs. Strauss? On the methodological and methodical matter of a distinction between two variants of Groundet Theory]. Historical Social Research/Historische Sozialforschung, 19, 157-177.

Thomas, G., \& James, D. (2006). Reinventing grounded theory: Some questions about theory, ground and discovery. British Educational Research Journal, 32(6), 767-795. doi:10.1080/01411920600989412

Tuckett, A. (2004). Qualitative research sampling: The very real complexities. Nurse Researcher, 12(1), 47-61.

Received July 10, 2012

Revision received December 10, 2012 Accepted December 10, 2012 